\title{
Time perspective, perceived stress, self-control and relationship satisfaction in heterosexual dating relationships of emerging adults
}

\author{
Aleksandra Huić ${ }^{1}$, Tina Krznarić ${ }^{1} \&$ Željka Kamenov ${ }^{1}$ \\ ${ }^{1}$ Department of Psychology, Faculty of Humanities and Social Sciences, University of Zagreb
}

\begin{abstract}
This study investigates possible protective and vulnerability factors in the link between perceived stress and relationship satisfaction in dating relationships of emerging adults. We investigate whether self-control, as a positive self-regulation resource, serves as a buffer mitigating the negative effect of stress on relationships. We posited a pathway model in which we examine whether maladaptive time-perspectives represent vulnerability factors leading to higher perceived stress which is in turn associated with impaired self-control and lower relationship satisfaction. In an on-line survey, we collected data on time perspectives, perceived stress, self-control and relationship satisfaction from 360 emerging adults in heterosexual dating relationships. Perceived stress was associated with impaired selfcontrol and lower relationship satisfaction. Past-negative, but not present-fatalistic perspective, was associated with more perceived stress which mediated the relationship between past-negative perspective and relationship satisfaction. However, adding this vulnerability factor to the model lead to self-control no longer having a significant buffering effect.
\end{abstract}

Keywords: Stress, relationship satisfaction; time-perspectives; self-control; dating relationships; emerging adults.

Perspectiva temporal, stress percebido, autocontrolo e satisfação relacional em relações de namoro de adultos emergentes heterossexuais: Este estudo analisa possíveis fatores de proteção e vulnerabilidade na associação entre stress percebido e satisfação relacional em relações de namoro de adultos emergentes. Investigamos se o autocontrolo, enquanto recurso positivo de auto-regulação, ajuda a mitigar o efeito negativo do stress nas relações. Propomos um modelo estrutural, no qual examinamos se perspetivas de tempo disfuncionais representam fatores de vulnerabilidade, levando a maior stress percebido, o que, por sua vez, poderá associar-se a menor autocontrolo e menor satisfação relacional. Num estudo online, recolhemos dados sobre perspetivas de tempo, stress percebido, autocontrolo e satisfação relacional de 360 adultos emergentes heterossexuais em relações de namoro. 0 stress percebido associa-se negativamente ao autocontrolo e à insatisfação relacional. Uma perspetiva passadanegativa (mas não presente-fatalista) associou-se positivamente à perceção de stress, que por sua vez mediou a associação entre a perspetiva passada-negativa e a satisfação relacional. No entanto, adicionar esse fator de vulnerabilidade ao modelo estrutural levou a que autocontrolo deixasse de ter um efeito significativo.

Palavras-chave: Stress; satisfação relacional; perspetivas de tempo; autocontrolo; relacionamentos amorosos; adultos emergentes.

Although having stable and supportive close relationships can protect individuals from the negative effects of stress (Cutrona \& Russell, 1988) and help them thrive (Feeney \& Collins, 2015), stress also has negative effects on relationship satisfaction (Randall \& Bodenmann, 2017). As such, it hinders the protective role of those same relationships. Married people consistently report lower relationship satisfaction at times of greater stress, both when the stress originates within and outside the relationship (Neff \& Karney, 2009). Furthermore, stress external to the relationship spills over into the relationship, and can even lead to marital dissolution (Bodenmann, 2000).

However, much less is known about the negative impact of stress or the associated mechanisms on younger (emerging) adults in dating relationships. Therefore, the present study examined the association between perceived stress and relationship satisfaction of emerging adults in dating relationships. Firstly, we were interested in the mechanism behind the expected negative association between subjective perception of stress and relationship satisfaction, and examined whether self-control, as a positive selfregulatory resource, has a protective, buffering role in the aforementioned association. Secondly, we

${ }^{1}$ Address for correspondence: Aleksandra Huic, Department of Psychology, Faculty of Humanities and Social Sciences, Ivana Lucica 3, 10000 Zagreb, Croatia. E-mail: ahuic@ffzg.hr 
extended previous studies by including possible individual vulnerability factors. Experience of stress is subjective and depends on our cognitive appraisal of a situation (Lazarus \& Folkman, 1984), and numerous individual traits serve as vulnerability factors shaping that perception for the worse (Williams, Smith, Gunn, \& Uchino, 2011). In this study, we investigated the role of time perspective, an individual's tendency to orient his or her perspective towards the past, present and/or future (Zimbardo \& Boyd, 1999), as such a vulnerability factor. To address this second goal, we tested a model to examine whether time perspective was associated with higher levels of perceived stress which in turn should be associated with lower relationship satisfaction, with self-control as a possible buffer in these associations. The results may have important implications for clinical and therapeutic work with couples under stress.

\section{Stress and intimate relationships}

Intimate relationships are influenced both by major and minor stress events (Randall \& Bodenmann, 2009). Major stress events include normative transitions and critical life events, such as severe illness, accidents, deaths, unemployment etc. (Dohrenwend \& Dohrenwend, 1974). Examples of minor stress events include daily hassles (e.g. being late, forgetting something), financial stress, stress related to friends, conflicts and frustrations experienced at work, and/or with extended family members or neighbors (Randall \& Bodenmann, 2009). However, regardless of major life events being considered as more intense, numerous studies show the impact minor daily stress exerts on our health and well-being is more pronounced (see Thoits, 2010 for review).

The same seems to be true for the impact of stress on intimate relationships. Studies do show good marital outcomes to be inversely related to stressful circumstances such as traumatic experiences (Lambert, Engh, Hasbun, \& Holzer, 2012), job loss (Doiron \& Mendolia, 2014), death of a parent (Umberson, 1995), death of a child (Rogers, Floyd, Seltzer, Greenberg, \& Hong, 2008), having a severely ill partner (Compas et al., 1994; Ybema, Kuijer, Hagedoorn, \& Buunk, 2002), or having a partner with mental health problems (Bodenmann, Charvoz, Widmer, \& Bradbury, 2004). However, more recent research seems to indicate that minor daily stress deteriorates couple functioning even more (see Randall \& Bodenmann, 2017 for review). One characteristic of minor daily stress is that it originates outside of the couple's relationship and as such is considered external to the relationship (Story \& Bradbury, 2004). Previous studies have found that couples report lower relationship satisfaction after periods of greater external stress (Karney \& Neff, 2013), and external, minor daily stress has the most significant impact on relationship quality and satisfaction (Randall \& Bodenmann, 2017). These findings are in line with Bodenmann's (2000) stress-divorce model, according to which minor stress events spill into the relationship, leading to alienation and lower marital quality in the short run, and to relationship dissolution in the long run.

This spillover effect happens in several ways. Experience of minor external stress cuts into the time needed for relationship maintenance. When stressed, spouses report having a more negative mood (Repetti, Wang, \& Saxbe, 2009) and feeling more socially withdrawn (Repetti, 1989) and angrier (Story \& Repetti, 2006). Under these conditions, partners are likely to spend less time together, resulting in fewer opportunities for sharing, exchanging intimacies or engaging in dyadic coping (Randall \& Bodenmann, 2009). Stress spillover effects also seem to deteriorate couple communication. People consistently report more negative communication and increased conflict in their relationships when stressed (Bodenmann, Ledermann, \& Bradbury, 2007; Bodenmann, Meuwly, Bradbury, Gmelch, \& Ledermann, 2010; Ledermann, Bodenmann, Rudaz, \& Bradbury, 2010).

Another important mechanism by which the experience of stress reduces relationship satisfaction is by impairing the ability to engage in self-regulatory processes (Karney \& Neff, 2013). Relationshippromoting behaviors require self-control (Finkel \& Campbell, 2001; Rusbult, Yovetich, \& Verette, 1996), but self-control is a limited resource that depletes with use (Baumeister, 2002). Thus, when self-control is depleted, such as because of stress at work or school, individuals are less able to control their behavior with their partner. Self-regulatory depletion is linked to less accommodation during relationship conflict (Finkel \& Campbell, 2001), as well as increased partner violence (Watkins, DiLillo, Hoffman, \& Templin, 2013). Studies on married couples confirm that self-regulatory skills deteriorate under conditions of greater stress, and that this mediates the negative association linking stress, negative relationship behavior and decreased relationship satisfaction (Buck \& Neff, 2012).

Most research about stress and intimate relationships has been conducted on married couples (e.g. Bodenmann, 2005; Bodenmann et al., 2004; Bodenmann et al., 2007; Buck \& Neff, 2012; Neff \& Karney, 2009; Story \& Bradbury, 2004). While this has yielded rich insights for married adults, it neglects the important developmental phase of early adulthood, when young people in premarital intimate dating relationships experience aspects of their possible future married roles (Arnett, 2000). This period of emerging adulthood has become even more important as modern generations date for longer periods 
before deciding to enter into marriage (Sassler, 2010). In 2015 in Croatia, an EU country in which our study was conducted, the average age of first marriage was 28 years for women, and 31 years for men (Croatian Bureau of Statistics, 2017). Since behaviors and lifestyles developed during emerging adulthood become consolidated and define long-term patterns associated with health outcomes later in life (see, for example, Lenz, 2004) it is important to devote more research attention to intimate dating relationships in emerging adulthood.

During their transition to adulthood emerging adults make career choices, learn how to navigate committed intimate relationships, assume more responsibilities and often juggle various social roles those of students, friends, children, partners, workers (Arnett, 2014). All these represent a possible source of stress (Bland, Melton, Welle, \& Bigham, 2012), and it seems that perceived stress levels are heightened during emerging adulthood (Asberg, Bowers, Renk, \& McKinney, 2008). Shulman and Connolly (2013) even propose that striving to integrate romance and life plans is one of the key development tasks during emerging adulthood. At the same time, studies which examine the effects of stress on relationship satisfaction in emerging adulthood are extremely scarce, and more attention needs to be given to both protective and vulnerability factors shaping these stress effects on dating relationships.

Available research has shown that, similar to what has been observed for married couples, stressful events are associated with greater stress levels and lower relationship satisfaction in dating relationships as well (Bahun \& Huic, 2017; Falconier, Nussbeck, Bodenmann, Schneider, \& Bradbury, 2015). One study showed that stress can also lead to behaviors that threaten existing dating relationships. Lewandowski Jr., Mattingly, \& Pedreiro (2014) experimentally manipulated stress levels of university students. Then the students were given the opportunity to interact with an attractive potential partner, and they were asked to list compliments about their current partner. Those under greater stress engaged in more flirtatious behavior with the potential partner and listed fewer compliments about their current partner.

These findings show there is a negative association between higher stress and relationship satisfaction among emerging adults in dating relationships, but they do not point to possible mechanisms of this negative effect in dating relationships. Thus, our first goal was to examine whether higher levels of perceived stress are associated with lower relationship satisfaction among emerging adults in dating relationships similarly to what has been reported among married adults, and to investigate a potential protective factor which might buffer that negative effect. In order to do so, we examined whether greater self-control (reflecting greater self-regulation skills) mediates the association between perceived stress and relationship satisfaction. Previous studies mainly investigated negative aspects of self-regulation by focusing on self-regulatory depletion (Karney \& Neff, 2013). Since greater self-control is associated with better adjustment, less pathology, and greater academic and interpersonal success (Tangney, Baumeister, \& Boone, 2004), we expected higher self-control to help preserve relationship satisfaction in the presence of stress. In other words, based on previous studies, we hypothesized that perceived stress would reduce relationship satisfaction both directly, and indirectly, by decreasing self-control (see Figure 1).

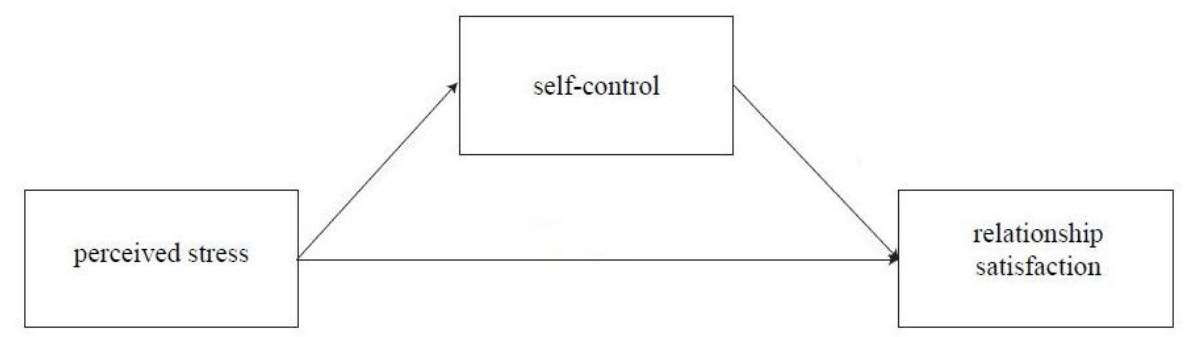

Figure 1. Hypothesized direct and indirect effects of perceived stress on relationship satisfaction, with the mediating effect of self-control

\section{Time perspective and perceived stress}

Lazarus and Folkman's (1984) definition of stress highlights that a situation will be perceived as stressful only if a person appraises the situation as too demanding, such as in the case of a threat, loss or damage to self; or if the person does not believe that he or she has adequate resources to cope with the demands of the situation. This conceptualization of stress as subjective and state-oriented has been expanded to include individual traits as factors of personal vulnerability which appears to be a precondition for perceiving a situation as stressful. For example, people with higher levels of neuroticism react more 
strongly to stressful events (Bolger \& Zuckerman, 1995; Suls \& Martin, 2005), as do people with higher levels of anger and hostility (Chida \& Hamer, 2008).

Another construct that may affect the perception of stress is time perspective, which refers to an individual's tendency to orient his or her perspective towards the past, present and/or future (Keough, Zimbardo, \& Boyd, 1999). Zimbardo and Boyd (1999) postulate that time perspective is adopted at an early age under the influence of culture, education and family, and that it affects judgments, decisions and actions (Nurmi, 1991). When coding, storing or recalling events and when forming expectations and goals, we apply time categories of past, present and future (Boyd \& Zimbardo, 2005). Ideally, an individual can exhibit a so-called balanced time perspective, flexibly choosing among the three time categories depending on the requirements of the situation, personal preferences and available resources. In reality, most people tend to overemphasize one of the time categories, resulting in a disposition or orientation towards the past, present or future (Zimbardo \& Boyd, 1999).

Zimbardo and Boyd (1999) identified five time perspectives. Past-positive, present-hedonistic and future time perspectives, due to their associations with positive life outcomes have been termed adaptive, while past-negative and present-fatalistic perspectives correlate with negative life outcomes and are thus referred to as maladaptive (Anagnostopoulos \& Griva, 2012; Olivera-Figueroa, Juster, Morin-Major, Marin, \& Lupien, 2015). Therefore, we decided to examine the latter two as vulnerability factors for perceiving situations as more stressful.

Past-negative individuals have a generally pessimistic and negative attitude towards the past. For example, they ruminate on past bad experiences and focus on past mistakes, think about what they could have done differently in their life or what they missed in their life, and compare good experiences in the present to bad experiences from the past (Zimbardo \& Boyd, 1999). They are prone to dissatisfaction, depression, aggression, low self-esteem and low emotional stability; they rarely experience pleasure, and they often have unsatisfactory interpersonal relationships and few friends (Zimbardo \& Boyd, 2008). Due to their fear that bad events will recur, they anticipate negative moods associated with similar future events (Stolarski, Matthews, Postek, Zimbardo, \& Bitner, 2014). Van Beek, Berghuis, Kerkhof, \& Beekman (2010) even suggest that a past-negative perspective may be the primary time-related factor contributing to anxiety.

Present-fatalistic individuals harbor an attitude of helplessness towards life and their own future, believing they have little or no control over the course of events in their lives. For example, they believe luck and destiny determine their future, have no sense of personal agency, and believe no personal action can improve their life (Zimbardo \& Boyd, 1999). These feelings of powerlessness often make such individuals depressed and anxious, resulting in hostility and aggression (Zimbardo \& Boyd, 2008). Such anxiety correlates strongly with stress (e.g. Bardeen, Fergus, \& Orcutt, 2013; Olson \& Surrette 2004).Both past-negative and present-fatalistic perspectives have been associated with negative moods, such as low arousal and higher levels of tense arousal (Stolarski et al., 2014), higher levels of anxiety (Åström, Wiberg, Sircova, Wiberg, \& Carelliand, 2014) and numerous psychiatric symptoms (van Beek et al., 2010). These two time perspectives seem to show an association with stress similar to its association with anxiety, implying that maladaptive time perspectives are associated with higher stress levels (Buhl \& Lindner, 2009). When faced with the same situation, higher perceived stress levels are elicited in past-negative and present-fatalistic individuals than in those with other time perspectives, both among adults (Papastamatelou, Unger, Giotakos, \& Athanasiadou, 2015) and adolescents (Andretta, Worrell, \& Mello, 2014). Also, both past-negative and present-fatalistic individuals tend to have lower self-efficacy and coping skills, which in turn leads them to perceive situations as demanding and results in higher stress levels (Epel, Bandura, \& Zimbardo, 1999; McKay, Percy, Cole, Worrell, \& Andretta, 2016).

However, some studies provide conflicting evidence with regard to the role of present-fatalistic perspective. A longitudinal study of individuals who experienced a traumatic event found that pastnegative time perspective was associated with higher levels of psychological distress even two years after the event, whereas a present-fatalistic perspective did not significantly affect levels of distress (Holman, 2015). Similarly, Åström et al. (2014) found a significant association of anxiety and stress with pastnegative perspective but not with present-fatalistic perspective. Given that these studies focused on more severe anxiety symptoms, rather then on stress symptoms, more research attention is needed to investigate the link between present-fatalistic time perspective and perceived stress.

In line with this, the second aim of our study was to investigate whether maladaptive time perspectives present vulnerability factors that increase stress levels, which in turn lower relationship satisfaction through impairing self-control. Based on previous research we focused on past-negative and present-fatalistic perspectives and hypothesized they would be associated with greater perceived stress as well as lower relationship satisfaction, given that these maladaptive perspectives are associated with lower life satisfaction and well-being (Sobol-Kwapinska, 2016), as well as with fewer, lower-quality close 
relationships (Holman \& Zimbardo, 2009). We also predicted that levels of perceived stress and selfcontrol would mediate the relationship between these two time perspectives and relationship satisfaction (see Figure 2).

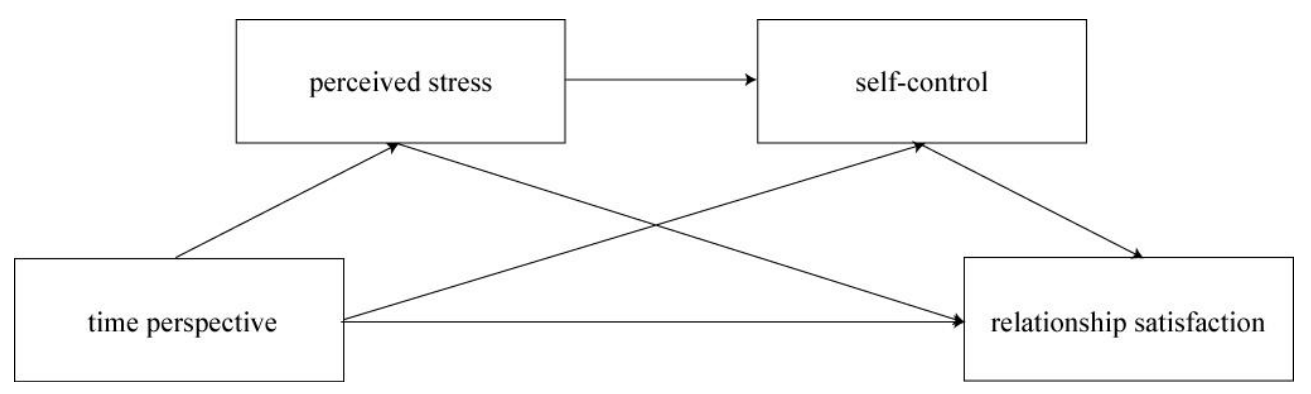

Figure 2. The full theoretical model tested in the study

\section{METHOD}

\section{Participants}

A total of 360 emerging adults (180 women) with an average age of 21.95 years $(S D=3.01$; range $18-31$ years) participated in the study. All were in a self-reported "serious" heterosexual dating relationship lasting an average of 29.6 months $(S D=23.57$; range: $1-102$ months); $12.5 \%$ were living with their partner at the time of the study. $48.1 \%$ of participants were currently living in Zagreb, the capital of Croatia, 6.9\% in other larger cities with up to 500000 inhabitants, $25 \%$ lived in smaller towns with less than 100000 inhabitants, and 19.4\% were living in villages. Most of the participants (38.6\%) grew up in the capital, $7.5 \%$ in other larger cities, $31.4 \%$ in smaller towns, and $22.5 \%$ in rural areas. The parents of $13.3 \%$ of the participants were divorced.

\section{Procedure}

This study was approved by the Ethics board of the Psychology Department, Faculty of Humanities and Social Sciences of the University of Zagreb. Study participants were recruited by psychology students among their acquaintances, resulting in a convenience sample of heterosexual emerging adults, mainly university students. Those heterosexual adults aged between 18 and 30 years who were dating but not married were approached. If potential participants reported that they were in a stable relationship (independent of its duration), they were asked to complete an online survey. At the beginning of the survey participants were informed about the main purpose of the study, assured of their anonymity and asked to provide informed consent to participate in the study. The on-line survey took 15 to 20 minutes to complete. Sample mortality was $1.7 \%$.

\section{Measures}

Time perspective was assessed using the Zimbardo Time Perspective Inventory (ZTPI) (Zimbardo \& Boyd, 1999). Respondents expressed their level of agreement with 56 items concerning beliefs, preferences and values using a 5 point scale ( 1 = very untrue of me, $3=$ neutral, $5=$ very true of me). The present study used the validated Croatian version of the ZTPI (Bunjevac et al, 2009). All five time perspectives showed good internal consistency in the present study: past-negative (such as in the item "Painful past experiences keep being replayed in my mind"), $\alpha=.84$; past-positive ("I get nostalgic about my childhood"), $\alpha=.70$; present-fatalistic ("It doesn't make sense to worry about the future, since there is nothing that I can do about it anyway"), $\alpha=.73$; present-hedonistic ("Taking risks keeps my life from becoming boring"), $\alpha=.78$; and future ("I am able to resist temptations when I know that there is work to be done"), $\alpha=.80$.

Perceived stress was assesed using the Cohen Perceived Stress Scale (PSS-14, Cohen, Kamarck, \& Mermelstein, 1983). The PSS-14 is the most widely used psychological instrument for measuring the perception of stress. It consists of 14 items that ask participants how often they found their lives unpredictable, uncontrollable, or overloaded in the last month. For example, one item is "In the last month, how often have you felt that you were unable to control the important things in your life?" Participants respond to these items on a 5 point scale ranging from 0 ("never") to 4 ("all the time"). 
Several items also ask respondents about current levels of stress experienced. Higher scores on the PSS14 indicate more perceived stress. The reliability of the scale in the present study was $\alpha=.83$.

The Brief Self-Control Scale (Tangney et al., 2004) is a unidimensional measure of trait self-control. It consists of 13 items, such as "I am good at resisting temptation" and "I say inappropriate things", for which respondents indicate how true each item is for them, using a 5-point scale from 1 ("does not reflect how I typically am") to 5 ("very much reflects how I typically am"). Higher scores indicate better selfcontrol. The reliability of the scale in the present study was $\alpha=.84$.

Relationship satisfaction was measured using the Relationship Satisfaction Scale (Rusbult, Martz, \& Agnew, 1998), a five item subscale of the Investment Model scales. This subscale measures the degree to which a relationship fulfills the respondent's needs for intimacy, sex, companionship, security and emotional involvement. Respondents indicate their degree of agreement with each item using a 9-point Likert scale from 1 ("completely disagree") to 9 ("completely agree"). The scale showed good reliability of $\alpha=.92$ in the present study.

\section{RESULTS}

\section{Descriptives}

Descriptive analyses and correlational data are shown in Table 1. Participants in our sample were largely satisfied with their relationships, and most reported intermediate levels of self-control. They reported sometimes feeling under stress during the preceding month, and had moderate levels of maladaptive time perspectives. These results are expected since our sample was recruited from a population of mainly healthy university students in stable relationships.

Bivariate correlations (see also Table $1^{2}$ ) showed that, as expected, higher levels of perceived stress were associated with lower self-control and relationship satisfaction. Higher self-control was associated with more relationship satisfaction. Being more fatalistic or oriented towards the negative past was associated with lower relationship satisfaction, while a more future orientation was associated with greater relationship satisfaction. The other time perspectives did not correlate with relationship satisfaction. Past-negative and present-fatalistic time perspectives correlated positively with perceived stress and negatively with self-control. Those more oriented toward the future reported having greater self-control, while those living in the moment (present-hedonistic) reported lower self-control.

Table 1. Correlations and descriptives among study variables.

\begin{tabular}{|c|c|c|c|c|c|c|c|c|}
\hline & PN & PP & PH & $\mathbf{P F}$ & $\mathbf{F}$ & PS & SC & RS \\
\hline Past - Negative & $()$. & $-.14^{* *}$ & $.14^{* *}$ & $.42^{* *}$ & -.02 & $.39^{* *}$ & $-.39 * *$ & $-.14^{* *}$ \\
\hline Past - Positive & & (.) & $.28^{* *}$ & .09 & $.15^{* *}$ & -.08 & .10 & .09 \\
\hline Present - Hedonistic & & & $()$. & $.42^{* *}$ & $-.19 * *$ & -.01 & $-.25^{* *}$ & -.00 \\
\hline Present - Fatalistic & & & & (.) & $-.23^{* *}$ & $.22^{* *}$ & $-.26^{* *}$ & $-.12^{*}$ \\
\hline Future & & & & & (.) & -.06 & $.44^{* *}$ & $.19 * *$ \\
\hline Perceived Stress & & & & & & (.) & $-.34^{* *}$ & $-.21^{* *}$ \\
\hline Self-Control & & & & & & & $()$. & $.21^{* *}$ \\
\hline Relationship Satisfaction & & & & & & & & $()$. \\
\hline $\mathrm{M}$ & 2.63 & 3.52 & 3.47 & 2.68 & 3.46 & 1.89 & 2.97 & 7.63 \\
\hline SD & 0.74 & 0.61 & 0.54 & 0.64 & 0.60 & 0.53 & 0.65 & 1.39 \\
\hline Range & $1-5$ & $1-5$ & $1-5$ & $1-5$ & $1-5$ & $0-4$ & $1-5$ & $1-9$ \\
\hline
\end{tabular}

Note. ${ }^{*} p<.05 ; * *<.01$.

$\mathrm{PN}=$ Past-Negative; $\mathrm{PP}=$ Past-Positive PH = Present-Hedonistic $;$ PF = Present-Fatalistic $; \mathrm{F}=$ Future; PS = Perceived Stress; SC = SelfControl; RS = Relationship Satisfaction

These results should be considered preliminary because they do not control for strong correlations among time perspectives. This covariation must be taken into account before detailed conclusions can be drawn about relationships among time perspectives, stress, self-control and relationship satisfaction.

\section{Perceived stress, self-control and relationship satisfaction}

In order to answer our first research question, we first explored associations among perceived stress, self-control and relationship satisfaction. Based on results from previous studies outlined in the introduction, we conducted a two-step hierarchical regression in which perceived stress was entered as a predictor of relationship satisfaction in the first step, followed by self-control as a predictor in the second

${ }^{2}$ We examined the same correlational patterns separately for women and men. Since there were no statistically significant differences (all Fisher Zs ranged from 0.32 - 1.95, n.s.) we report the results for the whole sample. 
step. ${ }^{3}$ Both steps were significant, with the two constructs explaining around $6 \%$ of variance in relationship satisfaction $\left(R=.25\right.$, adjusted $\left.R^{2}=.06, p<.01\right)$. There were no multicolinearity issues (all VIFs $<1.2)$. In the first step, perceived stress explained $5 \%$ of relationship satisfaction $(\beta=-.22, t=4.03, p<$ .001 ; adjusted $R^{2}=.05$ ). In other words, those who experienced greater stress reported lower relationship satisfaction. Adding self-control to the model significantly improved prediction $\left(\Delta R^{2}=.02, p=.02\right)$ and showed that having higher self-control contributed to higher relationship satisfaction $(\beta=.13, t=2.30, p$ $=.02$ ). At the same time, adding self-control to the analysis lowered the contribution of perceived stress to relationship satisfaction $(\beta=-.17, t=2.98, p=.003)$. This prompted us to perform further mediational analysis.

We tested for direct and indirect effects of perceived stress on relationship satisfaction, and we examined whether self-control mediates that relationship. We used bootstrap analysis (Preacher \& Hayes, 2008) to assess the significance of indirect effects. The reliability interval that does not include zero represented a significant indirect effect with $p<.05$.

As expected based on the regression analysis described above, perceived stress significantly affected relationship satisfaction $(b=-0.57, t=4.03, p<.001 ; L L C I=-.8481 ; U L C I=-.2917)$. More importantly, the indirect effect of perceived stress via self-control was significant $(b=-0.12$, Boot $L L C I=-$ .2256; Boot $U L C I=-.00429$ ). These results indicate that self-control was a significant mediator of the observed association between perceived stress and relationship satisfaction in our sample. Higher levels of perceived stress were associated with lower levels of self-control, which in turn reduced relationship satisfaction (Figure 3). This mediating role of self-control was only partial, explaining only $21 \%$ of the association between perceived stress and relationship satisfaction. Thus, perceived stress continued to exert a significant direct effect on relationship satisfaction in our sample even after controlling for selfcontrol $(b=-0.45, t=2.98, p<.01 ; L L C I=-.7433 ; U L C I=-.1521)$.

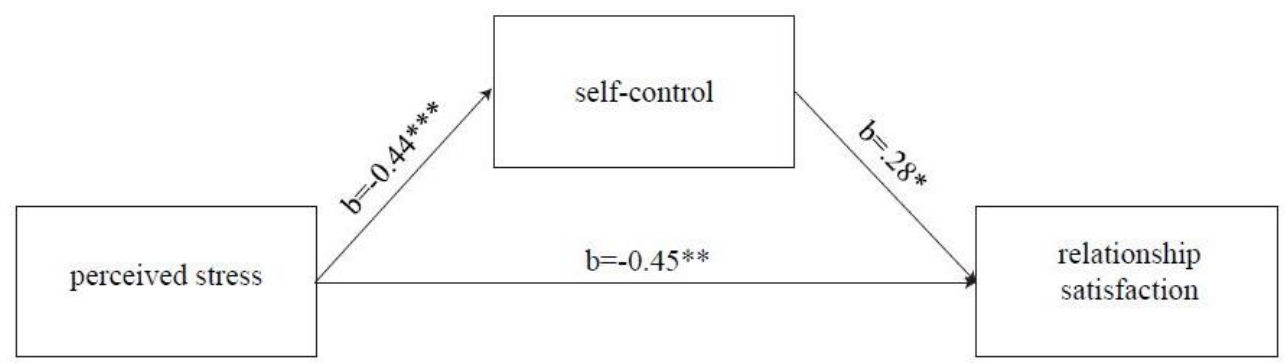

Figure 3. Direct and indirect effects of perceived stress on relationship satisfaction, with the mediating effect of self-control

$\left(N=328, b=\right.$ non-standardized regression coefficients, $\left.{ }^{*} p<.05,{ }^{* *} p<.01 ;{ }^{* * *} p<.001\right)$

\section{Time perspective as the vulnerability factor in the model of perceived stress - self-control - relationship satisfaction}

In order to test whether past-negative and present-fatalistic time perspectives may be the first link in the pathway connecting stress, self-control and relationship satisfaction we conducted two additional mediational analyses. Again, we used bootstrap analysis (Preacher \& Hayes, 2008) to assess the significance of indirect effects. The reliability interval that does not include zero represented a significant indirect effect with $p<.05$. We tested two serial mediational models. In the first, we tested whether pastnegative perspective indirectly affects relationship satisfaction via perceived stress and self-control (Figure 4). To control for the significant inter-correlations among all time perspectives, we entered the other four perspectives in the model as covariates.

The results showed that higher levels of past-negative time perspective (with other perspectives controlled for) were associated with greater perceived stress and lower self-control. However, this time perspective did not exert a significant direct effect on relationship satisfaction. Perceived stress was a significant mediator of the association between past-negative time perspective and relationship satisfaction $(b=-0.13 ; L L C I=-0.2501 ; U L C I=-0.0478)$. Being oriented towards the negative past was associated with greater perceived stress, which in turn was associated with lower relationship satisfaction. Nevertheless, the indirect effect of past-negative perspective on relationship satisfaction via

\footnotetext{
${ }^{3}$ As a control analysis, we also performed hierarchical regression in which relationship length was entered in the first step as a predictor of relationship satisfaction. Relationship length was not a significant predictor $(\beta=-.085, t=-1.541, n . s$. $)$. In fact, none of the bivariate correlations between relationship length and other study variables was significant $(r=.010-.108$; all $n . s$.). Therefore we did not control for relationship length in any analyses.
} 
perceived stress and self-control was not significant $(b=-0.02 ; L L C I=-0.0500 ; U L C I=0.0007)$. Thus, introducing past-negative time perspective into the model eliminated the significant mediating role of self-control between perceived stress and relationship satisfaction.

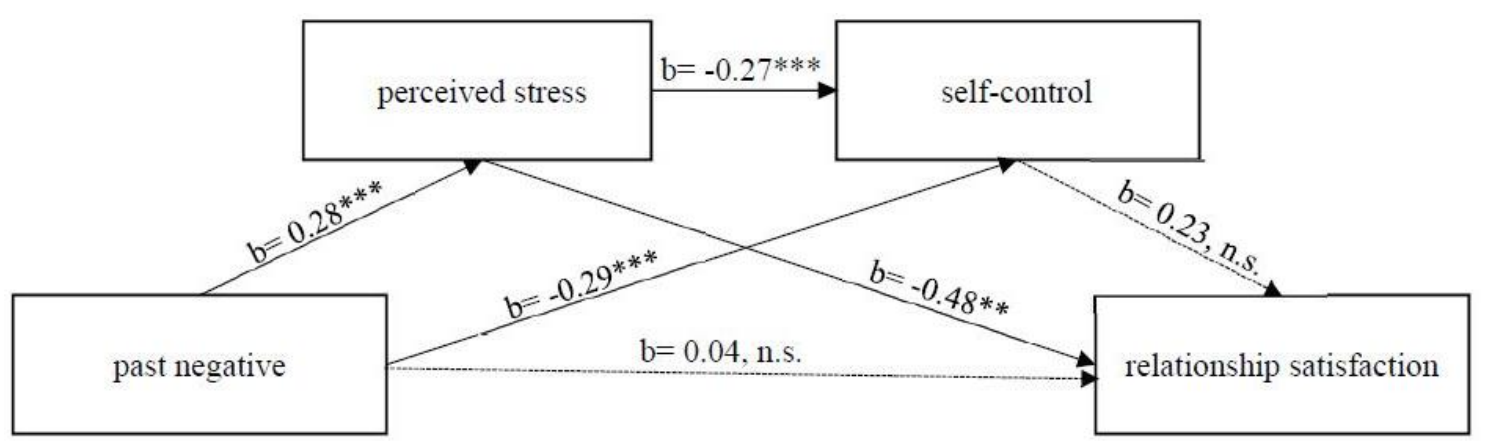

Figure 4. Direct and indirect effects of past-negative time perspective on relationship satisfaction, with the mediating effects of perceived stress and self-control

$\left(N=278, b=\right.$ non-standardized regression coefficients, $\left.{ }^{* *} p<.01 ;{ }^{* * *} p<.001\right)$

In the second mediational analysis, we tested whether present-fatalistic time perspective indirectly affected relationship satisfaction via perceived stress and self-control. Again, we controlled for other time perspectives. Present-fatalistic perspective was not significantly associated with perceived stress, selfcontrol, or relationship satisfaction (Figure 5). The only significant associations in the model were those of higher levels of perceived stress with lower self-control and lower relationship satisfaction. Indirect effects were not significant via perceived stress $(b=-0.04 ; L L C I=-0.1196 ; U L C I=0.0165)$ or via perceived stress and self-control $(b=-0.00 ; L L C I=-0.0227 ; U L C I=0.0011)$.

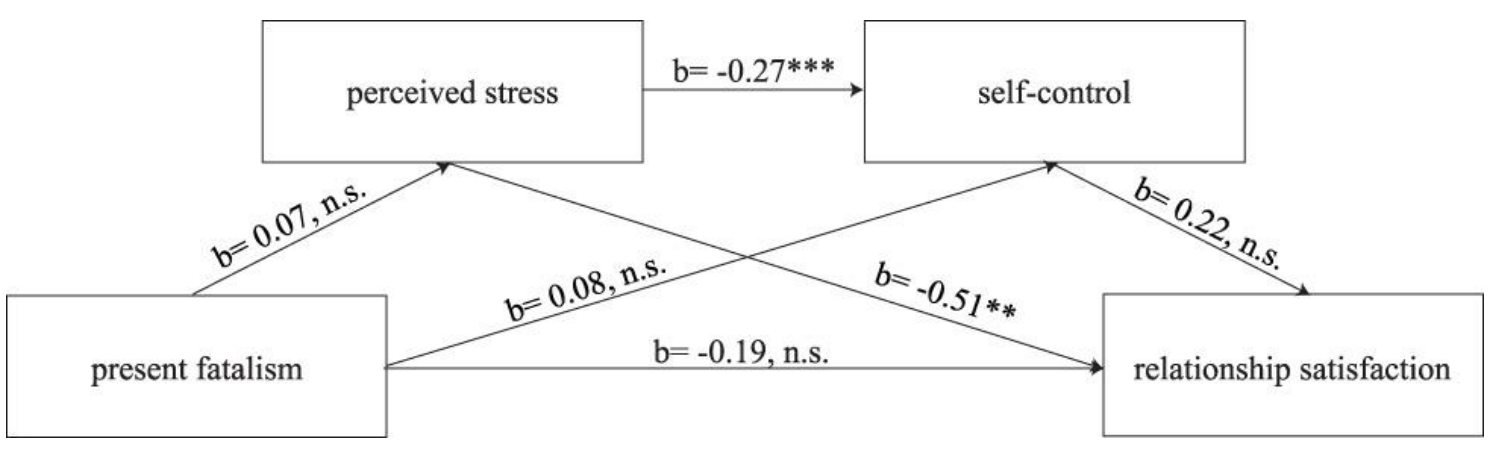

Figure 5. Direct and indirect effects of present-fatalistic time perspective on relationship satisfaction, with the mediating effects of perceived stress and self-control $N=278, b=$ non-standardized regression coefficients, ${ }^{* *} p<.01 ;{ }^{* * *} p<.001$

\section{DISCUSSION}

The first goal of this study was to extend the existing literature on the negative effects of stress on relationship satisfaction by investigating emerging adults in dating relationships, and the possible protective role of self-control. Our results confirm the patterns previously reported for married couples (see Karney \& Neff, 2013; Randall \& Bodenmann, 2017), and for dating relationships in emerging adulthood (Falconier et al., 2015; Shulman, Laursen, \& Dickson, 2014). Emerging adults in our study who reported greater percieved stress also reported lower relationship satisfaction. These subjective feelings of stress were associated with lower self-control, which in turn was associated with lower relationship satisfaction. Our results confirm that self-control processes are an important mediator of the negative effects of stress on relationship satisfaction, and that higher self-control helps buffer the negative effect of stress on relationship satisfaction.

We emphasize that all the effects in this study were quite small. This may reflect several characteristics of our sample. Participants were emerging adults who still do not shoulder the full responsibilities of adult working life and who are still largely dependent on their parents, perhaps even 
more so than in some other countries. Only slightly more than $10 \%$ of participants were living with their partners. The observed small effects in our study could also reflect our use of self-report questionnaires and a trait measure of self-control. Greater influence of perceived stress and self-regulatory mechanisms on the negative effects of stress on relationships has been reported in studies of married couples based on daily diaries of stressful experiences and measurement of relationship satisfaction over an extended period (for example, Buck \& Neff, 2012). Future studies on dating relationships should also consider using diary-based, longitudinal designs. Such data would encompass day to day behavioral observations and negative affect arising from minor daily stress, and would enable more nuanced analyses. Longitudinal data can give insight into causal connections which our study was not able to uncover.

Furthermore, some other constructs might be more important as buffers of the negative association between stress and relationship satisfaction. Social support is one factor whose protective role has been well documented in the stress literature (Thoits, 2010). Future studies should include not only individuals, but also couples, and investigate if supportive partner behavior mitigates the negative effects of stress on relationships. Moreover, intimate relationships which do not enjoy social support from external friends and family networks are also less satisfactory (Le, Dove, Agnew, Korn, \& Musto, 2010), and a lack of this external social support becomes an additional source of stress which spills over into the relationship and can lead to instability and breakup (Felmlee, 2001; Sprecher \& Felmlee, 2000). As Rodrigues, Lopes, Monteiro, and Prada (2017) recently showed, social support for relationships might be especially important for emerging adults, and early and middle emerging adults even differ in how much family vs. friends are important as sources of social support for their relationship commitment and stability. Investigating sources and the impact of social support on stress processes in intimate relationships in emerging adulthood seems to be a promising avenue for future studies.

The second goal of the present study was to explore whether time perspective may be a vulnerability factor in the pathway linking stress to reduced relationship satisfaction. We hypothesized that both the maladaptive past-negative and present-fatalistic time perspectives would be associated with greater perceived stress, which in turn would be associated with lower self-control and relationship satisfaction. Our results partially confirmed the hypothesis for the past-negative perspective, and did not support such a conclusion for the present-fatalistic perspective.

Our findings are consistent with other studies that found past-negative time perspective to be associated with greater stress (Papastamatelou et al., 2015) and anxiety (Van Beek et al., 2010). Pastnegative individuals tend to ruminate on negative experiences in their past, and this focus on previous bad experiences shapes their future expectations. They constantly relive bad experiences, remember how demanding and overwhelming they were, and expect bad things to happen again, which raises their stress levels. Therefore, it is not surprising that those with a stronger past-negative orientation also report more stress in their lives.

We found that past-negative individuals seem to have lower self-control, and to our knowledge, this is the first report of such a relationship. This finding is not surprising given the tendency of these individuals to ruminate on negative experiences and remain preoccupied with the past. This is surely exhausting for the individual, requiring a lot of energy. Since self-regulatory mechanisms should be viewed as a reservoir of energy that gets depleted, the reservoir of someone constantly preoccupied with the past - particularly with bad past events - is likely to be chronically depleted. This presumably leaves less energy for exerting adequate self-control in life, which may explain the observed negative association between past-negative time perspective and self-control.

Although hypothesized, past-negative perspective did not directly affect relationship satisfaction in our sample, but it did indirectly affect satisfaction via the mediating effects of perceived stress. Pastnegative individuals perceive more stress, leading to feelings of lower relationship satisfaction. A tendency to be oriented towards past negative experiences seems to be a vulnerability factor that affects the effect of percieved stress in intimate relationships in emerging adults.

The significant negative association between past-negative perspective and self-control raises the possibility that self-control is the mechanism behind the indirect effects of this time perspective on relationship satisfaction. Arguing against this, however, is our finding that adding past-negative time perspective as a predictor of relationship satisfaction in our model caused self-control to drop out as a significant mediator of the negative association between perceived stress and relationship satisfaction. This result should be considered preliminary, since it is based only on self-report and a trait measure of self-control. Future studies should verify and extend our results using analysis based on daily diaries or observation of behavior under real-life conditions. It is also possible that our results are biased by our use of a positive trait (self-control), rather than a negative trait (such as impulsivity) or negative experience (such as ego depletion). Negative traits and processes usually affect psychological experience more strongly than do positive traits and processes (Baumeister, Bratislavsky, Finkenauer, \& Vohs, 2001). We 
chose a positive operationalization of self-regulatory mechanisms for the present work because we wanted to extend and complement the literature, most of which is based on negative operationalizations (reviewed in Karney \& Neff, 2013). Our results suggest that the potentially protective effects of selfcontrol on relationship satisfaction is rather weak since it is masked by the negative effects of pastnegative time perspective. Future studies should examine these possibilities in greater depth.

Present-fatalistic time perspective did not seem to contribute to greater experience of stress or to relationship satisfaction in our sample. Although bivariate correlations suggested a significant negative association between this perspective and relationship satisfaction, the association became non-significant after we controlled for other time perspectives. Although we were surprised by the lack of association between present-fatalistic perspective and perceived stress, some other recent studies have also failed to detect an association of this perspective with stress or anxiety (Åström et al., 2014; Holman, 2015). It would appear that past-negative time perspective plays a larger role in the subjective experience of stress than present-fatalistic perspective does.

Although present-fatalistic time perspective may not be associated with perceived stress, it may still influence the ability to cope with stress. Strongly present-fatalistic individuals feel that destiny shapes their lives rather than their own actions, which makes them more likely to assess a given situation as too demanding and therefore stressful. While this may be a potentially adaptive response to situations that are, objectively, at least partly under the person's control, it can be regarded as a maladaptive response to situations that are, objectively, entirely beyond the person's control. This implies that an individual's ability to differentiate the two types of situations can be an effective coping strategy (Folkman, 1984). Our failure to detect significant correlations between a present-fatalistic time perspective and stress may be because this perspective is associated simultaneously with (a) negative cognitive appraisals of stressful situations as too demanding, and (b) the ability to assess a stressful situation as beyond one's control. Future research should examine whether this time perspective and stress show a curvilinear correlation, and they should investigate whether this perspective can serve as a coping mechanism. Such studies might experimentally vary the strength of this time perspective and measure the effects on perception of, and coping with, stressful situations that differ in how much they are under the individual's objective control.

The results of our study should be interpreted with caution because of several methodological limitations, including the reliance on self-report measures and a convenience sample of well-adjusted emerging adults in stable and satisfying relationships without excessive stress in their lives. The present study, like many others in this research area, may suffer selection bias because it included only individuals in committed and satisfying relationships. While such individuals are much more likely to consent to participate in such studies than those in less satisfying relationships or those under more stress, researchers should nevertheless strive to reduce this bias. Furthermore, our results might not generalize to all emerging adults, especially given our focus on stress in this study. It is possible that emerging adults who are still students differ both in sources of stress and levels of perceived stress from emerging adults who already work. The same is probable for those who still live with their parents and those who do not. Future studies should try to differentiate between these different subsamples, and strive to collect data in times of greater stress (e.g. for university students during exam periods).

Moreover, participants in our study were individuals and not couples. Although feeling under stress and feeling (un)satisfied with one's reltionship is shaped mostly by individual perception, relationship partners are interdependent (Kelley \& Thibaut, 1978). Not only do they influence each other's perception and behavior, but effective coping with stress also depends on the partners' behavior, and on common coping strategies used by the couple (Bodenmann, 2005). Future studies should investigate couples and employ dyadic designs in order to capture stress processes in emerging adulthood relationships more fully.

We emphasize the correlational nature of the present study, therefore no conclusions about the causal directionality of the observed associations can be drawn. This is true despite the fact that mediational models in this study assumed path directionality. While it is possible that higher levels of past-negative time perspective lead to higher levels of stress, it is equally possible that higher levels of stress lead a person to orient more towards negative experiences in the past. Indeed, certain traits associated with greater perceived stress (e.g. neuroticism) are also associated with putting oneself more often in stressful situations (Williams et al., 2011). Thus, it is possible that individuals with stronger pastnegative time perspective tend to put themselves in more stressful situations, leading them to experience more stress. Examining this possibility requires studies in which situational contexts and time perspectives are varied systematically.

Despite these limitations, the present work deepens our understanding of the negative effects of stress on relationship satisfaction in heterosexual dating relationships during emerging adulthood. We 
confirmed the importance of self-control as a self-regulatory mechanism and buffer against the negative effects of stress on relationships. We further showed that these buffering effects are likely to be weak, since they disappeared when we took into account individual vulnerability factors such as past-negative time perspective. It seems that self-control may not be a robust mechanism behind the association between stress and relationship satisfaction.

Perhaps the major contribution of our study is to show that past-negative time perspective is a vulnerability factor, not only for experiencing greater stress but also for the effect of that stress on close relationships. This is one of the few studies of time perspectives in the context of close relationships. Previous studies have shown that past-negative individuals have fewer, less supportive close relationships than those with past-positive, present-hedonistic or future orientations (Holman \& Zimbardo, 2009). In addition, past-negative individuals show patterns of insecure attachment, exhibiting greater avoidance behavior and experiencing greater anxiety towards friends and family, than do individuals with past-positive, present-hedonistic or future orientations (Akirmak, 2014; Laghi, D'Alessio, Pallini, \& Baiocco, 2009). Our study extends this literature by confirming that past-negative perspective plays an important role in relationship processes when we are under stress.

Our findings may have practical implications for counselors working with couples under stress. Practitioners may want to examine whether the individual is preoccupied about negative events in his or her past, and help him or her to stop ruminating about them. This by itself may lower the individual's subjective experience of stress, which may improve relationship satisfaction. Practitioners may also want to educate couples about the importance of self-regulatory mechanisms for relationship maintenance, as well as help couples develop coping strategies to quickly replenish their depleted reservoir of selfcontrol. This may help ensure that they have sufficient energy to exercise self-control even under stress, which may lead them to feel greater satisfaction in their relationship. Couples therapy may take into account individual time perspectives strenghtening the couples dyadic-coping mechanisms (Bodenmann \& Randall, 2012) to include an understanding of the partner's past - negative orientation. Since time perspective can be altered through interventions, a therapist might want to address this issue to diminish the perception of stress and to improve self- control and relationship satisfaction.

\section{REFERENCES}

Akirmak, U. (2014). How is time perspective related to perceptions of self and of interpersonal relationships?. The Spanish Journal of Psychology, 17, E92. http://dx.doi.org/10.1017/sjp.2014.92

Anagnostopoulos, F., \& Griva, F. (2012). Exploring time perspective in Greek young adults: Validation of the Zzimbardo time perspective inventory and relationships with mental health indicators. Journal of Social Indication Research, 106, 41-59. http://dx.doi.org/10.1007/s11205- 011-9792-y

Andretta, J. R., Worrell, F. C., \& Mello, Z. R. (2014). Predicting educational outcomes and psychological well-being in adolescents using time attitude profiles. Psychology in the Schools, 51(5), 434-451. http://dx.doi.org/10.1002/pits.21762

Arnett, J. J. (2000). Emerging adulthood: A theory of development from the late teens through the twenties. American Psychologist, 55(5), 469-480. http://dx.doi.org/10.1037/0003-066X.55.5.469

Arnett, J. J. (2014). Adolescence and emerging adulthood. Boston, MA: Pearson.

Asberg, K. K., Bowers, C., Renk, K., \& McKinney, C. (2008). A structural equation modeling approach to the study of stress and psychological adjustment in emerging adults. Child Psychiatry \& Human Development, 39(4), 481-501. http://dx.doi.org/10.1007/s10578-008-0102-0

Åström, E., Wiberg, B., Sircova, A., Wiberg, M., \& Carelli, M. G. (2014). Insights into features of anxiety through multiple aspects of psychological time. Journal of Integrative Psychology and Therapeutics, 2(1), 1-7. http://dx.doi.org/10.7243/2054-4723-2-3

Bahun, I., \& Huić, A. (2017). Intimate relationships in context: Stress spillover, relationship efficacy, and relationship satisfaction. Primenjena psihologija, 10(1), 5-16. http://dx.doi.org/10.19090/pp.2017.1.5-16

Bardeen, J.R., Fergus, T.A., \& Orcutt, H.K. (2013). Experiential avoidance as a moderator of the relationship between anxiety sensitivity and perceived stress. Behavior Therapy, 44(3), 459-469. http://dx.doi.org/10. 1016/j.beth.2013.04.001

Baumeister, R. F. (2002). Ego depletion and self-control failure: An energy model of the self's executive function. Self and Identity, 1(2), 129-136. http://dx.doi.org/10.1080/152988602317319302

Baumeister, R. F., Bratslavsky, E., Finkenauer, C., \& Vohs, K. D. (2001). Bad is stronger than good. Review of General Psychology, 5(4), 323 -370. http://dx.doi.org/10.1037/1089-2680.5.4.323

Bland, H. W., Melton, B. F., Welle, P., \& Bigham, L. (2012). Stress tolerance: New challenges for millennial college students. College Student Journal, 46(2), 362-376. http://dx.doi.org/10.1037/t39417-000 
Bodenmann, G. (2000). Stress und Coping bei Paaren [Stress and Coping in Couples]. Göttingen Germany: Hogrefe.

Bodenmann, G. (2005). Dyadic coping and its significance for marital functioning. In: Revenson, T. A., Kayser, K., \& Bodenmann, G. (Eds.). Couples coping with stress: Emerging perspectives on dyadic coping. American Psychological Association. http://dx.doi.org/10.1037/11031-002

Bodenmann, G., \& Randall, A. K., (2012). Common factors in the enhancement of dyadic coping. Behavior therapy, 43(1), 88-98. http://dx.doi.org/10.1016/j.beth.2011.04.003

Bodenmann, G., Charvoz, L., Widmer, K., \& Bradbury, T. N. (2004). Differences in individual and dyadic coping among low and high depressed, partially remitted, and nondepressed persons. Journal of $\begin{array}{lllll}\text { Psychopathology and } \quad \text { Behavioral } & \text { 75-85. }\end{array}$ http://dx.doi.org/10.1023/B:JOBA.0000013655.45146.47

Bodenmann, G., Ledermann, T., \& Bradbury, T. N. (2007). Stress, sex, and satisfaction in marriage. Personal Relationships, 14(4), 551-569. http://dx.doi.org/10.1111/j.1475-6811.2007.00171.x

Bodenmann, G., Meuwly, N., Bradbury, T. N., Gmelch, S., \& Ledermann, T. (2010). Stress, anger, and verbal aggression in intimate relationships: Moderating effects of individual and dyadic coping. Journal of Social and Personal Relationships, 27(3), 408-424. http://dx.doi.org/10.1177/0265407510361616

Bolger, N., \& Zuckerman, A. (1995). A framework for studying personality in the stress process. Journal of Personality and Social Psychology, 69(5), 890-902. http://dx.doi.org/10.1037/0022-3514.69.5.890

Boyd, J. N., \& Zimbardo, P.G. (2005). Time perspective, health, and risk taking. In A. Strathman \& J. Joireman (Eds.), Understanding behaviour in the context of time: Theory, research, and application (pp. 85-107). Mahwah: Lawrence Erlbaum.

Buck, A. A., \& Neff, L. A. (2012). Stress spillover in early marriage: The role of self-regulatory depletion. Journal of Family Psychology, 26(5), 698-708. http://dx.doi.org/10.1037/a0029260

Buhl, M., \& Lindner, D. (2009). Time perspectives in adolescence: Measurement, profiles, and links with personality characteristics and scholastic experience. Diskurs Kindheits- und Jungendforschung, 2, 197-216.

Bunjevac, T., Bokulić, M., Matić, J., Punek, J., Tomaš, T. \& Vrlec, A. (2009). Zimbardo time-perspective inventory. Unpublished manuscript.

Chida, Y., \& Hamer, M. (2008). Chronic psychosocial factors and acute physiological responses to laboratory-induced stress in healthy populations: A quantitative review of 30 years of investigations. Psychological Bulletin, 134(6), 829 -885. http://dx.doi.org/10.1037/a0013342

Cohen, S., Kamarck, T., Mermelstein, R. (1983). A global measure of perceived stress. Journal of Health and Social Behavior, 24, 385-396. http://dx.doi.org/10.2307/2136404

Compas, B. E., Worsham, N. L., Epping-Jordan, J. E., Grant, K. E., Mireault, G., Howell, D. C., \& Malcarne, V. L. (1994). When mom or dad has cancer: Markers of psychological distress in cancer patients, spouses, and children. Health Psychology, 13(6), 507-515. http://dx.doi.org/10.1037/02786133.13.6.507

Croatian Bureau of Statistics. (2017). Men and women in Croatia. Zagreb: Croatian Bureau of Statistics.

Cutrona, C. E., \& Russell, D. W. (1988). The provisions of social relationships and adaptation to stress. In W. H. Jones \& D. Perlman (Eds.), Advances in personal relationships (Vol. 1, pp. 37- 67). Greenwich, CT: JAI Press.

Dohrenwend, B. S., \& Dohrenwend, B. P. (1974). Stressful life events: Their nature and effects. John Wiley \& Sons. http://dx.doi.org/10.1016/0010-440X(84)90071-3

Doiron, D., \& Mendolia, S. (2014). Job loss and family dissolution. In Encyclopedia of quality of life and wellbeing research (pp. 3445-3448). Springer Netherlands. http://dx.doi.org/10.1007/978-94-0070753-5_4073

Epel, E.S., Bandura, A., \& Zimbardo, P.G. (1999). Escaping homelessness: The influences of self-efficacy and time perspective on coping with homelessness. Journal of Applied Social Psychology, 29(3), 575-596. http://dx.doi.org/10.1111/j.1559-1816.1999. tb01402.x.

Falconier, M. K., Nussbeck, F., Bodenmann, G., Schneider, H., \& Bradbury, T. (2015). Stress from daily hassles in couples: Its effects on intradyadic stress, relationship satisfaction, and physical and psychological well-being. Journal of Marital and Family Therapy, 41(2), 221-235. http://dx.doi.org/10.1111/jmft.12073

Feeney, B. C., \& Collins, N. L. (2015). A new look at social support: A theoretical perspective on thriving through relationships. Personality and Social Psychology Review, http://dx.doi.org/10.1177/1088868314544222

Felmlee, D. H. (2001). No couple is an island: A social network perspective on dyadic stability. Social Forces, 79(4), 1259-1287. http://dx.doi.org/10.1353/sof.2001.0039 
Finkel, E. J., \& Campbell, W. K. (2001). Self-control and accommodation in close relationships: An interdependence analysis. Journal of Personality and Social Psychology, 81(2), 263-277. http://dx.doi.org/10.1037/0022-3514.81.2.263

Folkman, S. (1984). Personal control and stress and coping processes: A theoretical analysis. Journal of Personality and Social Psychology, 46(4), 839-852. http://dx.doi.org/10.1037/0022-3514.46.4.839

Holman, E. A. (2015). Time perspective and social relations: A stress and coping perspective. In $M$. Stolarski, N. Fieulaine \& W. van Beek (Eds.) Time perspective theory; Review, research and application (pp. 419-436). New York: Springer International Publishing. http://dx.doi.org/10.1007/978-3-319-07368-2_27

Holman, E. A., \& Zimbardo, P. G. (2009). The social language of time: The time perspective-social network connection. Basic and applied social psychology, 31(2), 136-147. http://dx.doi.org/10.1080/01973530902880415

Karney, B. R. \& Neff, L. A. (2013). Couples and stress: How demands outside a relationship affect intimacy within the relationship In J. Simpson \& L. Campbell (Eds.) The Oxford Handbook of Close Relationships (pp. 664-684). Oxford: Oxford University Press. http://dx.doi.org/10.1093/oxfordhb/9780195398694.013.0030

Kelley, H. H., \& Thibaut, J. W. (1978). Interpersonal relations: A theory of interdependence. John Wiley \& Sons. http://dx.doi.org/10.1093/sw/25.3.245

Keough, K.A., Zimbardo, P.G., \& Boyd, J.N. (1999). Who's smoking, drinking, and using drugs? Time perspective as a predictor of substance use. Basic and Applied Social Psychology, 21, 149-164. http://dx.doi.org/10.1207/S15324834BA210207.

Laghi, F., D’Alessio, M., Pallini, S., \& Baiocco, R. (2009). Attachment representations and time perspective in adolescence. Social Indicators Research, 90(2), 181-194. http://dx.doi.org/10.1007/s11205-0089249-0

Lambert, J. E., Engh, R., Hasbun, A., \& Holzer, J. (2012). Impact of posttraumatic stress disorder on the relationship quality and psychological distress of intimate partners: A meta-analytic review. Journal of Family Psychology, 26(5), 729 -737. http://dx.doi.org/10.1037/a0029341

Lazarus, R. S., \& Folkman, S. (1984). Stress, appraisal, and coping. Springer publishing company. http://dx.doi.org/10.1007/978-1-4419-1005-9_215

Le, B., Dove, N. L., Agnew, C. R., Korn, M. S., \& Mutso, A. A. (2010). Predicting nonmarital romantic relationship dissolution: A meta-analytic synthesis. Personal Relationships, 17(3), 377-390. http://dx.doi.org/10.1111/j.1475-6811.2010.01285.x

Ledermann, T., Bodenmann, G., Rudaz, M., \& Bradbury, T. N. (2010). Stress, communication, and marital quality in couples. Family Relations, 59(2), 195-206. http://dx.doi.org/10.1111/j.17413729.2010.00595.x

Lenz, B. K. (2004). Tobacco, depression, and lifestyle choices in the pivotal early college years. Journal of American College Health, 52(5), 213-220. http://dx.doi.org/10.3200/JACH.52.5.213-220

Lewandowski Jr, G. W., Mattingly, B. A., \& Pedreiro, A. (2014). Under pressure: The effects of stress on positive and negative relationship behaviors. The Journal of Social Psychology, 154(5), 463-473. http://dx.doi.org/10.1080/00224545.2014.933162

McKay, M. T., Percy, A., Cole, J. C., Worrell, F. C., \& Andretta, J. R. (2016). The relationship between time attitudes profiles and self-efficacy, sensation seeking, and alcohol use: An exploratory study. Personality and Individual Differences, 97, 203-209. http://dx.doi.org/10.1016/j.paid.2016.03.060

Neff, L. A., \& Karney, B. R. (2009). Stress and reactivity to daily relationship experiences: How stress hinders adaptive processes in marriage. Journal of Personality and Social Psychology, 97(3), 435 450. http://dx.doi.org/10.1037/a0015663

Nurmi, J. (1991). How do adolescents see their future? A review of the development of future orientation and planning. Developmental Review, 11, 1-59. http://dx.doi.org/10.1016/0273-2297(91)90002-6

Olivera-Figueroa, L.A., Juster, R.P., Morin-Major, J.K., Marin, M.F. \& Lupien, S.J. (2015). A time to be stressed? Time perspectives and cortisol dynamics among healthy adults. Biological Psychology, 111, 90-99. http://dx.doi.org/10.1016/j.biopsycho.2015.09.002

Olson, A.C., \& Surrette, M.A. (2004). The interrelationship among stress, anxiety, and depression in law enforcement personnel. Journal of Police and Criminal Psychology, 19(1), 36-44. http://dx.doi.org/10.1007/ BF02802573

Papastamatelou, J., Unger, A., Giotakos, O., \& Athanasiadou, F. (2015). Is Time Perspective a Predictor of Anxiety and Perceived Stress? Some Preliminary Results from Greece. Psychological Studies, 60(4), 468-477. http://dx.doi.org/10.1007/s12646-015-0342-6 
Preacher, K. J., \& Hayes, A. F. (2008). Asymptotic and resampling strategies for assessing and comparing indirect effects in multiple mediator models. Behavior research methods, 40(3), 879-891. http://dx.doi.org/10.3758/BRM.40.3.879

Randall, A. K., \& Bodenmann, G. (2009). The role of stress on close relationships and marital satisfaction. Clinical Psychology Review, 29(2), 105-115. http://dx.doi.org/10.1016/j.cpr.2008.10.004

Randall, A. K., \& Bodenmann, G. (2017). Stress and its associations with relationship satisfaction, Current Opinion in Psychology, 13, 96-106. http://dx.doi.org/10.1016/j.copsyc.2016.05.010

Repetti, R. L. (1989). Effects of daily workload on subsequent behavior during marital interaction: The roles of social withdrawal and spouse support. Journal of Personality and Social Psychology, 57(4), 651-659. http://dx.doi.org/10.1037/0022-3514.57.4.651

Repetti, R., Wang, S. W., \& Saxbe, D. (2009). Bringing it all back home: How outside stressors shape families' everyday lives. Current Directions in Psychological Science, 18(2), 106-111. http://dx.doi.org/10.1111/j.1467-8721.2009.01618.x

Rodrigues, D., Lopes, D., Monteiro, L., \& Prada, M. (2017). Perceived parent and friend support for romantic relationships in emerging adults. Personal Relationships, 24(1), 4-16. http://dx.doi.org/10.1111/pere.12163

Rogers, C. H., Floyd, F. J., Seltzer, M. M., Greenberg, J., \& Hong, J. (2008). Long-term effects of the death of a child on parents' adjustment in midlife. Journal of Family Psychology, 22(2), 203 -211. http://dx.doi.org/10.1037/0893-3200.22.2.203

Rusbult, C. E., Martz, J. M., \& Agnew, C. R. (1998). The investment model scale: Measuring commitment level, satisfaction level, quality of alternatives, and investment size. Personal Relationships, 5, 357391. http://dx.doi.org/10.1111/j.1475-6811.1998.tb00177.x

Rusbult, C. E., Yovetich, N. A., \& Verette, J. (1996). An interdependence analysis of accommodation processes. In G. J. O. Fletcher \& J. Fitness (Eds.), Knowledge structures in close relationships: A social psychological approach (pp. 63-90). Mahwah, NJ: Erlbaum.

Sassler, S. (2010). Partnering across the life course: Sex, relationships, and mate selection. Journal of Marriage and Family, 72(3), 557-575. http://dx.doi.org/10.1111/j.1741-3737.2010.00718.x

Shulman, S., \& Connolly, J. (2013). The challenge of romantic relationships in emerging adulthood: Reconceptualization of the field. Emerging Adulthood, 1(1), 27-39. http://dx.doi.org/10.1177/2167696812467330

Shulman, S., Laursen, B., \& Dickson, D. J. (2014). Gender differences in the spillover between romantic experiences, work experiences, and individual adjustment across emerging adulthood. Emerging Adulthood, 2(1), 36-47. http://dx.doi.org/10.1177/2167696813515853

Sobol-Kwapinska, M. (2016). Calm down - It's only neuroticism. Time perspectives as moderators and mediators of the relationship between neuroticism and well-being. Personality and Individual Differences, 94, 64-71. http://dx.doi.org/10.1016/j.paid.2016.01.004

Sprecher, S., \& Felmlee, D. (2000). Romantic partners' perceptions of social network attributes with the passage of time and relationship transitions. Personal Relationships, 7(4), 325-340. http://dx.doi.org/10.1111/j.1475-6811.2000.tb00020.x

Stolarski, M., Matthews, G., Postek, S., Zimbardo, P. G., \& Bitner, J. (2014). How we feel is a matter of time: Relationships between time perspectives and mood. Journal of Happiness Studies, 15(4), 809-827. http://dx.doi.org/10.1007/s10902-013-9450-y

Story, L. B., \& Bradbury, T. N. (2004). Understanding marriage and stress: Essential questions and $\begin{array}{llll}\text { challenges. } & \text { Clinical } & \text { 1139-1162. }\end{array}$ http://dx.doi.org/10.1016/j.cpr.2003.10.002

Story, L. B., \& Repetti, R. (2006). Daily occupational stressors and marital behavior. Journal of Family Psychology, 20(4), 690 -700. http://dx.doi.org/10.1037/0893-3200.20.4.690

Suls, J., \& Martin, R. (2005). The daily life of the garden-variety neurotic: Reactivity, stressor exposure, mood spillover, and maladaptive coping. Journal of Personality, 73(6), 1485-1510. http://dx.doi.org/10.1111/j.1467-6494.2005.00356.x

Tangney, J. P., R. F. Baumeister, \& A. L. Boone (2004). High self-control predicts good adjustment, less pathology, better grades, and interpersonal success. Journal of Personality, 72 (2), 271-324. http://dx.doi.org/10.1111/j.0022-3506.2004.00263.x

Thoits, P. A. (2010). Stress and health: Major findings and policy implications. Journal of Health and Social Behavior, 51(1_suppl), S41-S53. http://dx.doi.org/10.1177/0022146510383499

Umberson, D. (1995). Marriage as support or strain? Marital quality following the death of a parent. Journal of Marriage and the Family, 57, 709-723. http://dx.doi.org/10.2307/353925 
van Beek, W., Berguis, H., Kerkhof, A., \& Beekman, A. (2010). Time perspective, personality and psychopathology: Zimbardo's time perspective inventory in psychiatry. Time and Society, 20(3), 364-374. http://dx.doi.org/10.1177/0961463X10373960.

Watkins, L. E., DiLillo, D., Hoffman, L., \& Templin, J. (2013). Do self-control depletion and negative emotion contribute to intimate partner aggression? A lab-based study. Psychology of Violence, 5(1), 35-45. http://dx.doi.org/10.1037/a0033955

Williams, P. G., Smith, T. W., Gunn, H. E., \& Uchino, B. N. (2011). Personality and stress: Individual differences in exposure, reactivity, recovery, and restoration. In: R. J. Contrada \& A. Baum (Eds.), The Handbook of Stress Science, Biology, Psychology and Health (pp. 231-245). New York: Springer Publishing Company.

Ybema, J. F., Kuijer, R. G., Hagedoorn, M., \& Buunk, B. P. (2002). Caregiver burnout among intimate partners of patients with a severe illness: An equity perspective. Personal Relationships, 9(1), 7388. http://dx.doi.org/10.1111/1475-6811.00005

Zimbardo, P., \& Boyd, J. (2008). The time paradox: The new psychology of time that will change your life. Simon and Schuster. New York: Free Press.

Zimbardo, P.G., \& Boyd, J.N. (1999). Putting time in perspective. A valid, reliable, individual-differences metric. Journal of Personality and Social Psychology, 77(6), 1271-1288. http://dx.doi.org/10.1037/0022-3514.77.6.1271

$\begin{array}{ll}\text { Historial do } & \text { artigo } \\ \text { Recebido } & 04 / 07 / 2017 \\ \text { Aceite } & 19 / 02 / 2018 \\ \text { Publicado } & 05 / 2018\end{array}$


Perceived stress in dating relationships

Esta página encontra-se propositadamente em branco 